\title{
LA MANUFACTURA TABACALERA CUBANA DURANTE LA SEGUNDA MITAD DEL SIGLO XIX
}

POR

\author{
DORIA GONZALEZ FERNANDEZ
}

Instituto de Historia de Cuba. La Habana

\section{INTRODUCCIÓN}

El creciente consumo internacional de tabaco que se operó durante el siglo XIX incidió directamente en la expansión de la economía tabacalera cubana, que en un proceso de crecimiento sistemático se ubicó como segundo renglón de importancia económica, llegando a representar el $20 \%$ de la riqueza productiva de la Isla. En este proceso el elemento de mayor trascendencia socio-económica había sido el desarrollo de una importante manufactura urbana, que en la medida que fue evolucionando se convirtió en el órgano vital de la rama en su conjunto, de forma tal que ya en el último tercio del siglo se estimaba que el valor de lo producido en la fase manufacturera, representaba el $52 \%$ de la economía tabacalera, calculada anualmente en 25.000.000 de pesos (1).

Tradicionalmente ubicada en zonas urbanas, fue en La Habana donde alcanzó su mayor esplendor, tanto por el número de establecimientos que llegó a concentrar, como por el hecho de constituir el núcleo por excelencia de la gran manufactura de exportación. En los años ochenta en el perímetro capitalino radicaban más de cien establecimientos de tabacos y cigarros con marcas firmemente acreditadas en el comercio. A diferencia de otras industrias, la elaboración del tabaco había promovido toda una serie de industrias auxiliares como la cajonera, la litografíca, la carpintería y ebanistería, etc., favoreciendo con ello no solo la

SIGL.A UTILIZADA:

ANC: Archivo Nacional de Cuba, La Habana.

(1) Memorias de la Unión de Fabricantes de Tabacos y Cigarros. Habana, 1894, pág. 28. 
diversidad y masividad de empleos (2), sino el surgimiento de un tipo de trabajador más calificado que el común de la época.

La historiografía ha advertido que desde mediados de siglo la industria tabacalera en Cuba había perfilado una serie de rasgos organizativos y estructurales que subsistieron en líneas generales hasta la penetración de los monopolios tabacaleros en las últimas décadas del siglo. En este sentido autores que han dedicado obras o reflexiones básicas acerca de la economía tabacalera como Fernando Ortiz, H. Friedlander, Gaspar J. García Galló, Julio Le Riverend, José Rivero Muñiz y Jean Stubbs han apuntado, de una u otra forma, el significativo proceso de concentración operado progresivamente en este sector, que se pudiera resumir en un proceso mediante el cual un grupo cada vez más reducido de empresarios fue contando con una mayor disponibilidad de recursos para la elaboración de tabacos, delineándose como un definido sector empresarial de notable relevancia en el acontecer político y económico de la colonia.

El propósito de este trabajo es precisamente analizar cómo se produjo este fenómeno, estudiando cuales fueron los resortes económicos que operaron en él, indagando acerca de cuales fueron sus condicionantes sociales y quienes las figuras que lo capitalizaron. En este sentido es importante fijar algunas cuestiones como la nota predominante, y hasta cierto punto peculiar, de este fenómeno fue la tendencia de estos empresarios en controlar las marcas de tabacos y cigarrillos que gozaban de crédito y por esta vía controlar el mercado. Por otra parte resulta interesante advertir dos fases bastante bien diferenciadas del proceso, una inicial de carácter nacional que se venía produciendo en los marcos financieros insulares, con capital básicamente radicado en Cuba; y otra fase, posterior, de mayor envergadura en la que intervinieron los monopolios tabacaleros absorviendo la mayor parte de las manufacturas cubanas consolidadas.

El trabajo se circunscribe esencialmente al primer momento que es el menos conocido (1860-1899). Las referencias que se hacen a la fase monopólica en realidad tienden a enfatizar el proceso anterior ya que, a nuestro juicio, el desarrollo alcanzado por las manufacturas insulares condicionó en buena medida el dinamismo de la penetración en este sector. Por último, aunque en la evolución de la industria tabacalera de este período hay

(2) Julio LE Riverend, Historia Económica de Cuba. La Habana, Instituto Cubano del Libro, 1974, pág. 366. Le Riverend asegura que hacia 1860 habia en las fábricas habaneras unos 15.000 operarios. 
sensibles diferencias con relación a procesos similares en la industria azucarera, el resultado a la larga fue el mismo, o sea el control del capital y la producción por una élite empresarial que había ido desplazando a productores con menos posibilidades. En general la penetración de los monopolios aceleró ese proceso en ambas industrias, modificándolo sustancialmente en la medida que resultó una vía de desindustrialización y desnacionalización importantes para el país.

Resultó muy útil la consulta del Registro Mercantil de La Habana, fondo que se encuentra en el Archivo Nacional de Cuba; así como las memorias de los fabricantes y la prensa tabacalera, en particular la revista El Tabaco. Como fuentes auxiliares se trabajó con directorios y anuarios mercantiles de diferentes años (3).

\section{RASGOS ORGANIZATIVOS DE LA MANUFACTURA TABACALERA A PARTIR DE 1850}

A diferencia de otras industrias, en la elaboración del tabaco en Cuba no se introdujeron reformas de tipo técnico que incrementaran la productividad del trabajo, e incluso en el sector cigarrero, de menor alcance, donde sí hubo una introducción tecnológica significativa desde 1853, se continuó recurriendo al empleo masivo de trabajadores. Este ensanche productivo, que respaldó durante décadas exportaciones anuales de 100 y 200 millones de tabacos, se produjo sobre la base del empleo extensivo de fuerza de trabajo. En 1860 la industria tabacalera sólo en La Habana aglutinaba 15.000 operarios, y ya hacia esa fecha comenzó a advertirse una tendencia cada vez mayor a la concentración de conglomerados obreros en establecimientos sensiblemente mayores, distinguiéndose por esos años la existencia de fábricas que podían emplear como promedio cincuenta o más trabajadores (4). El incremento de empleados por establecimiento promovió una especialización

(3) Especialmente valiosa resultó la colaboración de la Dra. Zoila Lapique Becali que facilitó información de su archivo personal y ayudó en la localización de materiales, poniendo a nuestra disposición su obra inédita Etiquetas cubanas de habanos y cigarrillos.

(4) Valentín Pardo y Betancour, Informe Ilustrado y estadístico que de orden del Sr. Intendente General del Ejército y Real Hacienda Isidro Walls, redactó y dio sobre los elementos de riqueza del tabaco en el año de 1861 y lo publicó en el presente. Habana, Imprenta el Tiempo, 1863. Este autor registra que en las 158 fábricas de primera clase con marcas establecidas en 1860, se empleaban 7.900 operarios, lo que apunta como promedio unos 50 obreros por establecimiento y da una ideal del grado de concentración obrera en determinados centros, pero las había aún mayores pues Sussini empleaba en 18632.500 operarios en sus instalaciones manufactureras. 
productiva mayor y fue en ese período donde se perfilaron los escogedores, fileteadores, rezagadores, torcedores, etc., como elementos distintivos del proceso de elaboración. No fue casual que hacia fines de la década del setenta los obreros se organizaran en gremios que atendieran a esa estructura(5).

Fue el carácter manual de la producción lo que imprimió una diversidad extraordinaria en los productos. «El tabaquero bueno es un artistan, se ha dicho con certeza y a mediados del siglo XIX ese aserto tuvo una especial connotación, ya que si en 1859 hay datos que aseguran que los torcedores elaboraban entre 12 y 16 vitolas diferentes, en 1890 había establecimientos en los que éstas pasaban de 150 (6). Los grandes establecimientos que comenzaron a aparecer por los años sesenta se construían con adecuados depósitos de amplias proporciones, para abastecer de materia prima continuamente al obrero y almacenar grandes volúmenes de productos terminados. Esos fueron los casos de la fábrica "La Excepción», de José Gener y Batet que empleaba como promedio unos 300 operarios y de "La Flor de Tabacos de Partagás», en la que su propietario Juan A. Bances llegó a tener en 1880 unos 1.200 obreros y cuya instalación se conserva todavía en la capitalina calle de Industria. Pedro A. Estanillo, en el mismo periodo empleaba alrededor de 400 obreros en cada uno de sus establecimientos de tabacos, "La Flor de Pedro A. Estanillo» y "La Flor de Fumar», entre otros.

Sin embargo el propio carácter manufacturero de la producción propició la existencia sistemática de la pequeña y mediana producción en el sector tabacalero, ya que los mecanismos de la competencia no hicieron incosteable las empresas de menor envergadura, porque en última instancia la productividad del trabajo era la misma en todos los establecimientos dedicados a esta actividad. Cerca de los grandes centros procesadores de tabaco, de hermosos frentes y grandes fondos, concebidos para emplear cientos de operarios y almacenar por miles los tercios de hojas vueltabajeras, orientados básicamente hacia el mercado mundial, gravitaban los pequeños y medianos establecimientos con muchos menos operarios -laborando una hoja más económica que desde mediados de siglo se denominaban chinchales- y talleres respectivamente.

(5) El Tabaco. 3 de octubre de 1899. Año I, no 3 pág. 19. En esta revista se comenta la importancia que por 1878 habían alcanzado los gremios de tabaqueros, rezagadores, escogedores, fileteadores, respectivamente.

(6) Antonio M. ${ }^{a}$ Gordon Y DE AcosTa El Tabaco en Cuba, apuntes para su hisıria. La Habana, La Propaganda Literaria, 1897. pág. 47; Vid. [3], pág. 19. 
Los últimos datos cuantificables que brindaron esa imagen contrastante datan de 1859, entonces ese tipo de establecimiento menor, sin marca acreditada, empleaba hasta ocho trabajadores. Con posterioridad hay continuas referencias de los marquistas a la existencia de fábricas "sin cuento» y fábricas de "barrio» que indican su perdurabilidad a todo lo largo del siglo (7). Estos pequeños centros se dedicaban a vender al menudeo, abasteciendo fundamentalmente al consumo interno, que era bastante amplio. La producción de tabaco, cigarrillo y picadura con ese destino consumía anualmente alrededor de $4.025 .000 \mathrm{~kg}$. de hoja insular, pero además elaboraban hoja procedente de México, Sumatra y Puerto Rico, lo importante era que fuese barata y "de rendimiento" (8).

Es decir que el surgimiento y desarrollo de la gran manufactura no implicó directamente la eliminación del pequeño productor, aunque sí sucedió en la industria azucarera en la que el elemento tecnológico jugó un papel catalizador en el proceso de concentración. Lo que se advierte en la manufactura tabacalera es una tendencia a la subordinación del pequeño productor con relación al "marquista», que fue colocando al pequeño productor en una posición subalterna con relación a su empresa. Ya en los años cincuenta había un pequeño grupo de "marquistas" y numerosos talleres sin marcas que producían para esos marquistas (9). Con posterioridad existen aseveraciones que apuntan este fenómeno como una práctica bastante generalizada por parte de la élite empresarial que adquiría la producción de distintos pequeños productores, sin marcas, y las comercializaban imprimiéndoles la suya, ya acreditada.

En la época se afirmaba acerca de los dueños de celebradas marcas como "Cabargas», "Partagás», "La Hija de Cabañas», "Carvajal», "La Higuera», entre otros... "es sabido que sus propietarios compran tabacos de fábricas menores, los seleccionan con gran cuidado y los envasan en cajas con sus propias marcas y obtienen por ellos los mismos precios que los que cargan por los produci-

(7) Estos datos aparecen en El Tabaco, $1^{\circ}$ de agosto de 1880. Año I, pág. 4; 13 de febrero de 1881. Año II $n^{Q} 21$, pág. 5; y en el 30 de enero de 1881 , año II $n^{Q}$ 19, págs. 5. Los datos relativos al ano de 1859 los publicó Pardo y Betancourt, vid. [3] y las referencias posteriores aparecen en El Tabaco. 15 de noviembre de 1880. año I, $n^{Q} 11$, pág. 2 y en la del 8 de mayo de 1881 . Suplemento del $n^{Q} 30$, pág. 2.

(8) El Tabaco. Diciembre de 1899. Año I, n² 5, págs. 20-21.

(9) Julio le Riverend, Historia Económica de Cuba. La Habana. Escuela del Comercio Exterior. MINCEX, 1963. pág. 168.

R. I., 1992, n² 194 
dos en sus fábricas» (10). De este fenómeno hay evidencias también en las últimas décadas del siglo, cuando se produjeron una serie de huelgas y los obreros se iban a trabajar a las llamadas "fábricas de barrio», con salarios «ínfimos», elaborando «las mismas vitolas... con el mismo esmero o más que en las fábricas de orden». Estos establecimientos vendían esa producción a los marquistas, que después de endosarles su propia marca, la comercializaban (11).

Es posible que esa relación de dependencia fuera reforzada a través de la refacción, que al perecer estuvo bastante extendida también en este sector, y era ejercida por marquistas y almacenistas sobre el pequeño y mediano productor por medio de préstamos o adelantos financieros que comprometían la entrega de la producción al refaccionista, para luego comercializarla a su favor.

La perdurabilidad de la pequeña y mediana producción, estimulada por la existencia de un significativo consumo interno y favorecida por la ausencia de elementos tecnológicos, inclina a pensar que los resortes de la competencia se orientaron básicamente en otra dirección. La existencia de un sector del ramo, que fue acumulando mayores recursos y capital y se fue enfrascando en negocios cada vez mayores, estaba más vinculado al crédito de la producción, focalizándose una acusada lucha por la adquisición de marcas que legitimaran la calidad de la mercancía y garantizaran una segura realización de la misma. La preocupación central del productor residía en acreditar o adquirir las marcas, ampliándolas todo lo posible. En este sentido el productor que no las tenía, ni contaba con posibilidades financieras para adquirirlas o acreditarlas, no representaba un problema. Lejos de ello el marquista podía emplear ventajosamente sus esfuerzos, adquiriendo su producción a bajo precio y multiplicando a su haber la inversión al comercializarla bajo el título ya reconocido de su marca, y en ese sentido el marquista estimulaba también esa producción.

La disputa económica se ventilaba fundamentalmente entre los productores que pretendían acreditarse en el mercado, para lo cual necesitaban controlar la mayor cantidad de marcas aceptadas por el consumo y en función de ello desplazar del giro a

(10) Hunt's and Merchants' Magazine and Commerce Riview (XL) pág. 283. Citado por Levi Marrero, Cuba: Economía y Sociedad. Madrid Editorial Playor, 1984, tomo XI, pág. 75.

(11) El Tabaco. 8 de mayo de 1881. Suplemento del nº 30 pág. 2. 
aquellos que no lograban mantener el nivel requerido por las normas de la competencia. En este sentido las marcas no eran solamente un signo distintivo del producto, sino que eran consideradas jurídicamente una propiedad mueble y se acreditaban al fabricante por medio de un documento denominado "certificado de la marca», que expedía el Capitán General. El ensanche productivo de que fue objeto el tabaco elaborado había dado lugar a una creciente especulación con las marcas, que no era más que la expresión de la creciente competencia que acaecía en el sector. Los textos de las numerosas disposiciones que se promulgaron y los incontables pleitos que existieron acusan esta tendencia (12).

En la medida que se fueron delineando las mejores marcas -o sea aquellas que denominaban productos de óptima calidad para el consumidor - éstas comenzaron a representar un plusvalor. De hecho el productor de una marca reconocida lograba precios de mercado que superaban su propio valor. Por citar un caso la marca «Flor de Tabacos Partagás» tenía precios de venta que eran cinco $u$ ocho veces superiores al costo de elaboración (13).

La orientación preferente de la mejor producción tabacalera era el mercado mundial, era notorio en la época que muy pocos de los tabacos producidos en las fábricas famosas eran consumidos en la isla. Durante la segunda mitad del siglo los ingresos anuales por la vía de las exportaciones de tabaco manufacturado

(12) Sobre legislación marcaria puede consultarse: Real Decreto de 20 de noviembre de 1850. Ministerio de Comercio, Instrucción y Obras Públicas. Publicado en la Gaceta de La Habana el 24 de enero de 1851. Circular del Gobierno Político de La Habana de 5 de septiembre de 1856, publicado en la Gaceta de La Habana el 6 de septiembre de 1856; Circular del Gobierno Político de La Habana con fecha de 14 de octubre de 1856, publicado en la Gaceta de La Habana el 15 de octubre de 1856; Resolución del Gobierno Político de La Habana el 8 de marzo de 1870, en el ANC, fondo Gobierno General leg. $158 \mathrm{n}^{\mathbf{2}} 7967$; Real Orden de 31 de marzo de 1882 aprobando el Reglamento para la Instrucción de las Marcas de los productos de la Industria, en la Gaceta de La Habana de 18 de mayo de 1882, Real Decreto de 21 de agosto de 1884. Una buena parte de estas disposiciones están reproducidas en el libro de Angel González DEL VALLE, titulado Memorandum presentado a la Comisión Nacional de Propaganda y Defensa del Tabaco Habano, La Habana, Imprenta El Siglo XX, 1929. También è Mario Díaz IrIzar. Comentarios a las Leves de Marcas y Patentes. Edición Oficial. 1917. No obstante en el Archivo Nacional se conservan numerosos expedientes que recogen los pleitos por usurpaciones de marcas, trampas, fraudes etc., En 1883, por sólo citar una irregularidad la famosa marca "La Intimidad" de Antonio Caruncho aparecía registrada también a nombre de un tal Vicente Viejo.

(13) El Tabaco. 19 de junio de 1881. Año II, n 34, pág. 2. 
llegaban a los 12.000 .000 de pesos, en tanto que el valor de la producción consumida en la isla era de 1.500 .000 (14).

Julio Le Riverend ha señalado que inicialmente se produjo una absorción de algunas marcas por parte de los fabricantes más capacitados, para hacer frente a los inconvenientes de la competencia. En la década del setenta hemos rastreado casos concretos de la concentración de marcas en determinados productores, en detrimento de sus antiguos dueños, como Juan B. Romero que en 1874 había adquirido las marcas de tabacos que en 1860 estaban registradas a nombre del marquista Ramón Díaz, tituladas "La Cosmopolita» y "La Española». Esta última resultó la marca principal del establecimiento de Romero y en pocos años llegó a lanzar muchas más al mercado. El importante fabricante de tabacos Pedro Murias no aparecía registrado como tal en 1860, sin embargo en 1874 ya había adquirido la fábrica y marcas de la Compañía de Tajo y Quevedo estableciendo "La Meridiana" como marca principal de su establecimiento y ampliando rápidamente las marcas acreditadas.

Fue entre 1860 y 1874 cuando surge quien sería uno de los más importantes marquistas del último tercio del siglo, Ramón Allones, sobre idénticas bases, es decir adquiriendo marcas de productores que salían del giro, en este caso las de un tal Abreu. Por su parte los hermanos Cueto en ese período adquirieron las marcas de dos antiguos fabricantes, Felix Arnau y Manuel Reina, llegando a concentrar un total de dieciséis marcas y estableciendo "La Granadina» como marca principal de su establecimiento. En este período se destacó también Manuel Marinas, adquiriendo las marcas de José Bengochea, y en 1874 llegó a concentrar un total de quince marcas. Tanto Reina como Arnau y el resto de los productores que dieron sus marcas desaparecieron de los registros de fabricantes (15).

La concentración de las marcas en un reducido sector indica la concentración de la producción, ya que no tenía mayor trascendencia dónde se elaboraba el tabaco, sino a título de quien se detentaban las ganancias. En la práctica el marquista disponía de la producción elaborada en sus propias instalaciones y de toda la producción que pudiese adquirir para acreditarla. Resultaba frecuente que con el éxito empresarial se produjese una ampliación

(14) Vid. [I] págs. 28-29.

(15) Directorio de Artes Comercio e Industria de la Habana, La Habana, Litografía de Tiburcio V. Cuesta, 1860. Y Directorio General y Comercial de La Habana e isla de Cuba. La Habana, Imprenta Militar, Depósito General, 1874. 
de la capacidad productiva. Lamentablemente no se conoce el peso proporcional de las distintas manufacturas en el volúmen de producción elaborada, pero parece lógico afirmar que el mayor volúmen de producción se lograba en aquellos centros en los que se concentraban cientos de obreros y coinciden con los de las marcas más cotizadas; Gener, Bances, Carvajal, H. Upmann, Estanillo y otros.

No obstante en la medida que se incrementaba la competencia se advierte una tendencia a la fusión de capitales entre distintos productores por la vía de la asociación. El productor aislado, aún cuando tuviera un número aprecible de marcas, se encontraba en condiciones más vulnerables para difundir y de hecho mantener su producción que los grupos de productores asociados. Sobre el manufacturero pesaban cuantiosos tributos que debía pagar por diversos conceptos; la contribución directa se regulaba al $5 \%$ para las propiedades destinadas a la producción de tabacos y el impuesto transitorio era de un $5 \%$ sobre las utilidades líquidas. La contribución municipal fue ascendiendo con los años, y estaba sujeta a una serie de arbitrariedades, a lo que habría que agregar los problemas con la fuerza de trabajo y el elevado costo que fue adquiriendo la materia prima.

De modo que la tendencia fue ir a la asociación. En este sentido la perdurabilidad de las marcas estuvo muy vinculada a esta forma de organización y la asociación de capitales. A la vez que comienza a indicar la existencia de un proceso de centralización de capitales expresaba un determinado proceso de concentración de la producción, en la misma medida que propiciaba un incremento en la disponibilidad de capital para emplear más operarios y adquirir materia prima, encontrándose estos productores en mejor posición para difundir la producción.

\section{LAS SOCIEDADES MERCANTILES}

La existencia de sociedades para la explotación del tabaco estaban algo extendidas en Cuba a mediados del siglo XIX. En los Directorios de Industria y Comercio publicados en 1859 y 1860 se registraban una serie de establecimientos ya fueran dedicados a la manufactura o el comercio que funcionaban a través de este tipo de organización empresarial. Sin embargo de lo que se trata hacia los años setenta es de la formación de sociedades que comienzan a combinar en su seno capitales de diversas 
procedencias, ya fuera agrícola, manufacturero o comercial, ampliándose los negocios hacia todas las fases del sector.

En sentido general eran sociedades encomanditas, donde tanto las pérdidas como las utilidades estaban en proporción con el volúmen de capital aportado por cada socio. Se evidencia en ellas el incremento de las utilidades y el frecuente traslado de las instalaciones a lugares de mayores proporciones. Su rasgo más notorio fue la acumulación de marcas, que eran aportadas por uno o varios asociados, y en el trascurso de la sociedad se iban adquiriendo otras marcas, ya fuese por la vía de compras, adjudicación de empresas, arrendamiento o matrícula de nuevas marcas. Es este el proceso que en buena medida respalda la transformación del marquista en empresario industrial, al que no era casual encontrar entre las figuras políticas insulares de primera línea del período, ya fuera en instituciones económicas -como la Cámara Oficial de Comercio y Navegación de La Habana- o en instituciones militares - como el Cuerpo de Voluntarios- o formando parte de la directiva de partidos políticos como el Reformista o Unión Constitucional: todos, nucleados en el órgano del sector, la pujante Unión de Fabricantes de Tabacos.

Las sociedades estudiadas denotaban prosperidad y la viabilidad del proceso en curso: Juan Cueto y Collado por ejemplo, que con su hermano había adquirido por los años setenta las marcas de Arnau y Reina, había fomentado una serie de sociedades. En 1882 se adjudicaba, por la disolución de una de ellas, una fábrica de tabacos con la marca "Flor de Navas", y sus marcas anexas "Obeso y Cueto", "D. Quijote de la Mancha» e "Invitación», creando en ese mismo año otra sociedad en comandita bajo la razón de Cueto y Cía. con un comerciante de tabaco en rama, Antolín del Collado y Obeso, vecino de Consolación del Norte y dueño de vegas tabacaleras. El capital inicial de esta sociedad fue de 27.307 pesos aportados por mitad por cada uno de los socios, en la que la parte que correspondía a Cueto fue representada por el crédito de las marcas, el valor del establecimiento, enseres, efectos y mercancías en su poder. Collado participaba con el capital líquido en onzas de oro. Tres años después prorrogan esta sociedad con un capital de 37.537 pesos y ampliaban el número de marcas con la adquisición de "Dios Marte», "La Perfección», y "Guerra Bella». En 1889 las ganancias eran de 57.167 pesos (16).

Fue a través de la formación de progresivas sociedades que

(16) ANC. Fondo Registro Mercantil de la Habana. 1. a sección, tomo I, folio 100, hoja 23. 
Manuel Valle y Fernández logró un considerable grado de capitalización en la elaboración y venta de tabacos, explotando la marca "Flor de Cuba». En 1880 la explotaba en sociedad con Segundo Alvarez y desde esa fecha comenzó a gozar de crédito en las principales plazas de Estados Unidos, Inglaterra, América del Sur y otras naciones europeas; en esos años obtuvo medallas de oro en las exposiciones internacionales de París, Filadelfia y Viena. Los precios de las vitolas de "La Flor de Cuba" llegaron a cotizarse, las extrafinas hasta 400 pesos el millar, las finas entre 70 y 35 y las corrientes entre 52 y 36 .

En 1884 ya Manuel Valle creaba de manera independiente una sociedad titulada "Manuel Valle y Fernández», en la que él era el único gerente, aportando todo el capital que ascendía a 80.000 pesos y ampliando el negocio a la elaboración de cigarrillos y picadura bajo la reconocida marca y sus anexas. Un rasgo distintivo de sus empresas fue la promoción de empleados experimentados, incluso tabaqueros, como socios industriales, que paulatinamente se fueron encargando de la administración, con participación en las utilidades. Por ejemplo en la sociedad formada en 1884, Valle se quedaba con el $82 \%$ de las utilidades y distribuía el $18 \%$ entre tres de sus socios, todos ellos empleados sin aporte inicial de capital. En 1886 había aumentado el número de marcas y se prorrogaba la sociedad ampliándola hasta la fase agrícola con la incorporación entre los socios de un propietario de vegas, José Paula Arias, de Pinar del Río, que participaba con la rama para la elaboración de tabacos y cigarros, pero además recibía un porcentaje de los tercios vendidos por la sociedad, lo que indica que la misma comenzó a dedicarse también a la venta de la rama. En esta ocasión la sociedad había elevado su inversión a 139.965 pesos y trasladó el establecimiento de la calle Gervasio a la céntrica de Galeano, a un edificio mucho mayor, acorde con las perspectivas de la empresa. Su éxito fue rotundo, en 1890 Valle efectuó una nueva prórroga y esta vez la sociedad contaba con una inversión de 200.000 pesos y nuevas marcas matriculadas. Ese volúmen de capital se mantuvo después con la sociedad "Viuda de Valle y Fernández», en vísperas de la guerra, y llegó prósperamente a 1898 (17).

Otro caso interesente es el del marquista Segundo Alvarez,

(17) ANC. Fondo Registro Mercantil de la Habana. 1. a sección, tomo II, folio 161, hoja 71. La informaciaón sobre el crédito de su marca y los precios de sus vitolas en: El Tabaco. 13 de marzo de 1881. Año II, $n^{\circ} 25$, pág. 2; y el 15 de octubre de 1880 , año I, $n^{9} 8$, pág. 1. 
quien había consolidado capital a través de la sociedad con Valle para la elaboración de tabacos con la marca "La Flor de Cuba", y en los años ochenta era uno de los prominentes hombres de negocios de la isla, lo que le valió para ser nombrado presidente de la Cámara Oficial de Comercio y Navegación de La Habana, además de ser uno de los fundadores del Gremio de Fabricantes de Tabaco que surgió por esta fecha. En 1882 adquirió con Perfecto Fernández y López la fábrica y marcas de tabaco y cigarros "La Corona» que había pertenecido a la compañía de Antonio Cabarga. En 1885 ambos crearon la sociedad mercantil Segundo Alvarez y Cía. para la explotación y giro de dicha marca y anexas "Flor de Manuel López y Cía.", "José Domingo", "La Alhambra», "Katherine and Petruchio" y "Punch», comprendiendo la elaboración y venta de los productos. Esta sociedad se constituyó con un capital de 80.000 pesos aportados por mitad entre los dos socios, pero el gerente y socio general era Alvarez que aportaba capital y las marcas acreditadas; López participaba con algún capital y las instalaciones.

En el transcurso del primer año de constituida la sociedad inscribió dieciocho marcas más, muchas de ellas compradas a la extinta sociedad de López y Fernández. En 1888 instalaron una máquina para hacer cigarros corrientes que producía un millar de cigarrillos por minuto; al año siguiente Alvarez prorrogó la empresa pero ya con un capital de 189.000 pesos dando participación a López como gerente y dedicando a los empleados más sobresalientes el $17 \%$ de las utilidades. En 1895 se registraba otra prórroga, esta vez con un capital de 199.000 pesos y unas cuarenta marcas entre las de tabacos, cigarros y picadura. Se había nombrado como gerente en esta ocasión al antiguo administrador y empleado Emilio Barrios para que representase la sociedad, percibiendo por ello una discreta participación en las utilidades. En 1898 el negocio prosperaba y se volvió a prorrogar sobre las bases anteriores (18). Por su parte la sociedad mercantil «Pino y Villamil» creada en 1884, resultó una combinación de capital mercantil y manufacturero. En esa fecha Juan Pino y Lomba y Domingo Villamil y Pérez constituyeron la empresa con el objetivo de elaborar tabacos bajo la marca "La Africana" y sus anexas, con un capital de 35.000 pesos en los que Pino participó con existencias en rama, instalación, muebles y el crédito de las marcas, todo evaluado en 25.000 pesos y el comerciante Villamil aportó en efectivo los 10.000 restantes. En este caso ambos 17.

(18) ANC. Fondo Registro Mercantil de La Habana. Tomo I, folio 65, hoja 
socios aparecían como gerentes y administradores y las utilidades se distribuían mitad para la gerencia y la otra mitad era invertido en la empresa, contabilizándose individualmente el incremento de capital en proporción al aporte inicial de cada uno. Entre 1884 y 1893 inscribieron doce marcas más, Villamil representaba a la sociedad en Cayo Hueso donde se ocupaba de la venta de los productos. En 1890 la envergadura de la empresa los lleva a delegar en el dependiente Manuel Carreño las funciones administrativas que antes ellos desempeñaban. En 1893 liquidaron la sociedad y crearon otra bajo la misma razón por un período de cinco años pero ahora con un capital de 70.000 pesos, en la que el mencionado administrador participaba ya como socio, con un aporte de 11.000. Al culminar el tiempo convenido fue liquidada, dando su haber a Carreño y se creó otra sociedad, con el mismo título y nuevas marcas, esta vez por diez años, con un capital de 90.000 pesos con la inclusión de otro comerciante, Manuel Lozano Muñiz. Desde los años noventa habían tenido que trasladar la manufactura a un edificio mayor en la céntrica calle de San Miguel (19).

Otra combinación de capital manufacturero y mercantil la protagonizaron las distintas sociedades fundadas por Pedro Bances Suárez, dueño de la famosa marca y fábrica "La Carolina", con el comerciante Cayetano Suárez Rodríguez. Ambos estaban asociados desde la década del setenta en la elaboración y venta de tabacos con esa marca. En 1882 prorrogaron la sociedad nombrada Bances y Suárez, con un capital de 114.667 pesos por cuatro años, después de haber mudado el establecimiento a una instalación de altos y bajos con dos locales contiguos y de haber estimado las utilidades anuales en 18.917 pesos, como promedio. En 1886 ya se dedicaban a la producción de cigarrillos y paquetes de picadura y en 1890 contaban con 23 marcas más que las registradas inicialmente, algunas de ellas adquiridas por títulos de compra-venta al ex-fabricante José Chinchilla y Díaz de Oñate (20).

Otra modalidad de la centralización del capital lo fue sin duda la creación de empresas que integraban en sí otras sociedades. En 1883 se creó la sociedad de Inclán, Díaz y Cía. para la elaboración de tabacos con la marca "Flor de Inclán y Trinidad", integrada por Francisco Inclán Castro, dueño de la fábrica y marcas y Joaquin Díaz Alvarez, que participaba por sí y por la

(19) ANC. Fondo Registro Mercantil de La Habana. tomo II, folio 33, hoja 47.

(20) Ibidem, tomo III, folio 87, hoja 116. 
sociedad Pérez Díaz y Alvarez, de la que él era gerente. La entidad representada por Joaquín Días aportaba a la sociedad Flor de Inclán y Trinidad capital en efectivo y tabaco en rama. $\mathrm{Al}$ disolverse en 1889 por vencer el plazo convenido se valoraron las utilidades en 42.447 pesos sobre un desembolso inicial de 32.135 (21).

Pudieran citarse muchos más ejemplos de esta forma de organización del capital para explotar integralmente el negocio tabacalero, pero los casos señalados ilustran en buena medida lo más representativo y resulta interesante detenerse con más detalle en el proceso de centralización de capitales, pero vistos a través de sus propios protagonistas.

\section{LOS MARQUISTAS Y LA CENTRALIZACIÓN DE CAPITALES}

La literatura histórica no ha sido pródiga en cuanto al tratamiento de las figuras que tuvieron por base los negocios tabacaleros, los pocos nombres que han llegado a nuestros días están cuando más asociados a la perdurabilidad de alguna que otra marca famosa, alguno es mencionado accidentalmente en los textos. Sin embargo, durante la segunda mitad del siglo XIX fue precisamente un grupo de hombres de empresa dedicados a este negocio los que hicieron posible con su competencia y capital que el habano llegase a las regiones más distantes del globo, llegando a constituir un sector muy definido de intereses que tuvo mucha más incidencia en la vida económica y política de la colonia de lo que comunmente se piensa.

En el último tercio del siglo el reducido grupo de marquistas que había capitalizado, consolidando un espacio seguro en el comercio, fueron aquellos que como norma desbordaron los marcos propios de la manufactura. Entre los primeros fabricantes que extendieron sus intereses al sector agrícola se encontraron Jaime Partagás, Anselmo González del Valle, José Cabargas y Joaquín Barreras, según noticias aportadas por Pardo y Betancourt en 1859, y es conocido entre 1862 y 1877 «fue cuando los industriales $\mathrm{H}$. Upmann, Bock, Murias, Gener y otros consolidaron las tierras tabacaleras para sus florecientes negocios de exportación» (22).

(21) Ibidem, tomo III, folio 60, hoja 90.

(22) Jean STUBBs, Tobacco on the periphery. A case study in Cuban labour history. 1860 - 19.58. Cambridge University Press, 1985. 
En los años setenta Miguel Jané había formado diversas sociedades mercantiles para la elaboración y venta de tabacos con Gener, Romulo Bosh y su hermano Marcelino Jané (23). En los años ochenta explotaba la marca "La Majagua" y tenía una de las grandes instalaciones del período en la céntrica calle de Prado frente a la India; sus vitolas más finas se cotizaban a 500 pesos el millar. En ese año ya era un prominente hacendado tabacalero, contando con importantes terrenos en Consolación del Sur.

La sociedad de B. Pérez y Cía. que se dedicaba a la elaboración de tabaco, estaba registrada por esa fecha entre los siete propietarios más significativos de tierras tabacaleras de San Juan y Martínez (24). No fue en modo alguno casual que cuando la Diputación Provincial de Pinar del Río se interesó en que la Empresa de Ferrocarril del Oeste extendiera hasta la Herradura la línea que entonces llegaba hasta la Soledad, encontrara entre los marquistas una extraordinaria acogida, hecho que les permitó asegurar a la prensa que el cumplimiento de sus propósitos se realizaría en plazo mucho más breve que los pensados inicialmente. Inmediatamente Miguel Jané y Leopoldo Carvajal ofrecieron por medio de una suscripción "los recursos necesarios» para la obra, garantizando el importe de 900 a 1.000 toneladas de railes de acero para las obras. La suscripción fue respaldada rápidamente por los fabricantes Elías Valle, la viuda de Morales, Francisco Pérez del Río, Manuel Valle y Cía., Jané, Carvajal entre otros. Se esperaba de inmediato el respaldo de Julián Alvarez, Juan B. Romero, Bances, los hijos de González del Valle, y de Juan Conill «todos - comentaba la prensa- tienen estrechas relaciones con la Vuelta de Abajo» (25).

El interés de los marquistas por adquirir tierras tabacaleras se fue reforzando, en la década del ochenta. Rivero Muñiz asegura que distintos propietarios de manufacturas «comenzaron a dedicar parte de las ganancias obtenidas, a la adquisición de vegas, ampliando los cultivos y asegurándose de ese modo la materia prima indispensable para sus industrias» (26). En los años noventa la prensa hace alusión frecuentemente a la cantidad de los vegueríos que tenían notables marquistas como Calixto López,

(23) ANC. Fondo Gobierno General. Leg. 435 n² 2108, leg. 449, n² 21.495; leg. $443 \mathrm{n}^{\mathrm{o}} 21.495$.

(24) El Tabaco. $1^{0}$ de agosto de 1880. Año I, $\mathrm{n}^{0} 3$, pág. 8.

(25) El Tabaco. 16 de enero de 1881. Año II n² 17, pág. 3

(26) José Rivero Muñiz, El Tabaco, su historia en Cuba. La Habana, Instituto de Historia de Cuba, Academia de Ciencias de Cuba, 1965, tomo II, pág. 313. 
propietario de la famosa fábrica de cigarrillos «El Edén»; y era el caso también de D. ${ }^{a}$ Antonia López, propietaria de la renombrada fábrica de tabacos «Por Larrañaga». Así como del potentado José Gener, con su famosa finca "El Hoyo de Monterrey» de la que ya se decía que no había en ... «la Vuelta de Abajo nada que lo mejore" (27).

La propiedad de las vegas era lógicamente un elemento importante de provisión de tabaco en rama, que garantizaba la economía de recursos. En el último tercio del siglo se estimaba que el costo de la materia prima representaba el $50 \%$ del costo total de elaboración; por otra parte la tenencia de las vegas era una garantía de la calidad del producto. Y hay otro plano del problema bastante inexplorado, que es la relación entre el marquista y el veguero, este último vivía en las condiciones más precarias, endeudado la mayor parte del tiempo a cuenta de los préstamos y adelantos que le hacía el marquista y le comprometía cada cosecha. Esta situación de explotación inspiró a poetas como Joaquín Lorenzo Luaces que expresó en su poema «Marquista y vegueros».

Como enjambre de auras verdes

agoreras de la muerte

En tubatey se presentan

los marquistas exigentes;

y con el oro en la mano

compran la cosecha en ciernes,

Por el precio miserable

que a cosecha en flor conviene

No cubre tus compromisos

aquel oro insuficiente

y te ves, pronto, Genaro,

En el mismo mar que siempre.

La propiedad de las vegas representaba además otra fuente de ingresos al poder dedicar una parte de la rama a la comercialización. Esto es de suma importancia pues si bien la elaboración del tabaco torcido se debatió durante las últimas décadas del siglo bajo los efectos de la política fiscal y comercial española y la creciente competencia de la poderosa industria tabacalera norteamericana, en contrapartida las exportaciones de tabaco en

(27) El Tabaco. 15 de noviembre de 1899. Año I nº 4, pág. 21. 
rama fueron estimuladas sistemáticamente a través de los mismos aranceles que entorpecían la salida del producto terminado. De modo que el negocio de las exportaciones de materia prima comenzó a ser también una alternativa empresarial de los marquistas, y los almacenes de tabaco en rama para la exportación se fueron definiendo como pujantes entidades comerciales en las que había invertidos "fuertes capitales" (28).

En 1880 se contaban en La Habana 67 almacenes de tabaco en rama, estos establecimientos se dedicaban a refaccionar a los vegueros y a los pequeños y medianos productores. Entre los más importantes almacenistas se contaban fabricantes como Leopoldo Carvajal, Juan Conill, José Gener, Obeso, Bengochea, entre otros. Así que cuando se piensa en el empresario tabacalero del último tercio de siglo, o sea aquel que conformó el sector dominante que perduró en líneas generales hasta la irrupción de los monopolios, hay que tener en cuenta este proceso previo de integración de capital, pues muchos de los que vendieron sus empresas habían avanzado en la cohesión de las distintas fases del sector. Esa pujanza económica les permitió un rápido ascenso en las estructuras sociales y políticas de la sociedad y en buena medida explica la notoriedad que llegaron a tener.

Una figura ilustrativa de este proceso fue, sin duda, D. Leopoldo González Carvajal y Zaldúa, marqués de Pinar del Río, quien aparece registrado como fabricante a mediados de la década del setenta con una fábrica de tabacos en la concurrida Calzada del Monte, donde llegó a emplear hasta 2.000 operarios para explotar la marca "Carvajal y Carvajal». Desde fines de esa década y hasta finales del siglo aparece formando sociedades mercantiles en las que él aportaba todo el capital y se dedicaban, como reza en las inscripciones «a todos los negocios de lícito comercio" (29). En 1880 tenía importantes inversiones agrícolas en la provincia de Pinar del Río, para la explotación de la hoja, por lo que entre 1880 y 1881 pidió autorización al gobierno para construir un muelle particular y almacenes en el puerto de Dimas, al norte de esa provincia, para facilitar sus prósperos negocios de exportación. En La Habana contaba con extensos almacenes en la céntrica calle de Monte, que explotaba a través de una sociedad mercantil bajo la razón de Carvajal y Cía., que radicaba en la calle de Obrapía. Sus negocios de elaboración de tabacos se fueron ampliando, matriculando nuevas marcas, en $1883 \mathrm{su}$

(28) Vid. [12], pág. 36.

(29) ANC. Fondo Registro Mercantil de La Habana. Tomo II, folio 62, hoja 53. 
marca principal de tabacos era "Leopoldo Carvajal» y en esos años adquirió la famosa fábrica de tabacos y cigarros «Hijas de Cabañas y Carvajal", para la que se confeccionaban lujosas vitolas para la exportación, cotizadas entre 100 y 500 pesos el millar en las plazas de Inglaterra y los Estados Unidos. Desde el punto de vista político este prominente hombre de negocios fué miembro destacado del partido Unión Constitucional, senador y diputado de la isla, y presidente en 1884 de la Unión de Fabricantes de Tabacos (30).

Otra figura interesante resultó ser Juan Conill, pionero en el establecimiento de los primeros almacenes de tabaco en rama para la exportación desde la década del cuarenta, invirtió capital también en tierras tabacaleras y en los años ochenta era ya un importante empresario que continuaba incrementando su capital a través del giro comercial con grandes almacenes de tabaco en rama para la exportación en la calle de Teniente Rey. Ya en 1880 sus negocios se habían extendido a la elaboración de tabacos, estableciendo una fábrica en la localidad rural de Bejucal, donde explotaba la conocida hoja de "partidos». El éxito alcanzado le permitió asociarse con Manzanedo en negocios de exportación de tabaco a España, y llegó a incursionar en la banca, hay documentos acerca de que en mayo de 1882 constituyó con su hijo una sociedad mercantil para dedicarse a este tipo de negocio, con un capital inicial de 1.115 .739 pesos. También se conoce que estuvo asociado con José R. Almiral en asuntos de petróleo (31).

Por su parte José Gener y Batet era propietario de la famosa fábrica de tabacos y cigarros "La Excepción», a la vez que poseía tierras excepcionales para el cultivo del tabaco en la provincia de Pinar del Río; su hermano R. Gener y Batet tenía una fábrica de cigarros en el mismo período y ambos giraban en la esfera comercial con almacenes de tabaco en rama para la exportación bajo la firma de Hermanos Gener. José Gener fue durante años capitán de Voluntarios y su vocación integrista fue firmemente acuñada cuando presidió la Comisión que sentenció a fusilamiento a los estudiantes de medicina en 1871 (32).

La evolución económica que protagonizaron marquistas de la

(30) El Tabaco. 25 de octubre de 1880. Año I, n² 9, pág. 2; 13 de marzo de 1881. Año II, $n^{Q} 25$, pág. $6 ; 15$ de agosto de 1880 . Año I, ne 4 , pág. 1 .

(31) ANC. Fondo Registro Mercantil de La Habana, tomo III, folio 108, hoja 63. Y. Aurea FERNÁNDEZ España y Cuba, 1868 - 1899. La Habana, Editorial Ciencias Sociales, 1988. pág. 106.

(32) Ver Luis F. Le Roy y Gálvez, A cien años del fusilamiento de los estudiantes de medicina La Habana, Editorial de Ciencias Sociales, 1971, pág. 138. 
importancia de Pedro A. Estanillo, Juan Antonio Bances y H. Upmann, enriquecen la diversidad y envergadura del proceso descrito: Pedro A. Estanillo y Trueba había iniciado sus primeras incursiones en el sector tabacalero en 1869, matriculando la marca de cigarrillos "Espacial Pectoral de Berro», que en poco tiempo se convirtió en una de las más demandadas por el consumo insular.

Por esos años contaba con un solo operario, sin embargo la calidad de sus productos y la dedicación que imprimía a la empresa rindió pronto sus frutos y ya en 1870 hay noticias de que empleaba entre cincuenta y cien operarios. Así continuó ampliando su manufactura hasta que en 1880 contaba ya con 900 cigarreros y diez máquinas que representaban el trabajo de 160 hombres «sin que el resultado de la tarea de tan crecido número de obreros, sea suficiente a llenar los pedidos que hoy tiene esta empresa industrial" (33). La solidez económica que había logrado le permitió abrir una fábrica de tabacos titulada "La Flor de P. A. Estanillo». Y en 1880 ampliaba aún más sus negocios formando una sociedad mercantil con los empresarios Benito Celorio y Gustavo Bock para la adquisición de otra fábrica de tabacos, titulada "Flor de Fumar", que había sido propiedad de Leoncio Barrueta (34). No se conoce que Estanillo tuviese en ese período propiedades agrícolas, pero su socio industrial Bock sí.

De conjunto se estimaba que Estanillo empleaba en los años ochenta unos $578.000 \mathrm{~kg}$. de rama de Vuelta Abajo para la fabricación de tabacos y cigarros, y daba trabajo en sus instalaciones entre 1.300 y 1.400 personas, en las que habían más de diez máquinas movidas a vapor (35). En 1883 liquidó los asuntos de la sociedad Bock, Celorio y Cía., adjudicándose las marcas de tabacos "Flor de Fumar", "The Raleigh", "El Príncipe Dolgorouff", "La Predilecta», "Flora Africana», "La Fraya», "La Lechuza», y "La Oportuna", creando otra sociedad, esta vez titulada Estanillo y Cía. con un capital de 100.000 pesos aportados integramente por él y con la participación de Juan Valle Fernández, quien tenía la función de socio comanditario y administrador de la fábrica. Esta sociedad tenía como objetivo económico la elaboración y venta de tabacos con las marcas antes compartidas y que ahora eran de Estanillo, además por esta fecha disfrutaba de muchas

(33) El Tabaco, 30 de enero de 1881. Año II, n 19, pág. 5.

(34) El Tabaco, 15 de agosto de 1880. Año I, n² 4, pág. 5.

(35) El Tabaco. 30 de enero de 1881. Año II n 19, pág. 5. 
más que había obtenido por la vía del arriendo. La utilidad de esta empresa ascendía a mediados de los años ochenta a 149.105 pesos (36).

Otro de los marquistas importantes del período lo fue sin duda Juan Antonio Bances Alvarez de quien se decía en 1880 «en la industria, en el comercio, en la banca, el Sr. Bances ocupa un primer lugar, y su voto y su opinión, son atendidos en cuanto tienen relación con los intereses morales y materiales del país» (37). Bances procedía de una familia española acomodada. En la isla sus hermanos tenían sólidos negocios en el comercio tabacalero desde la década de los años cincuenta. Juan Antonio había acumulado capital a través de la participación en distintos negocios comerciales de tabaco conjuntamente con ellos, lo que le permitió establecer una fábrica de tabacos en Nueva York en los años cincuenta que giraba con la marca "Los Tres Hermanos», de la que se dijo en la prensa «que había adquirido muy pronto justo crédito" (38). De regreso a Cuba a fines de esos años, y sin haber abandonado nunca el giro comercial, entró en sociedad con el marquista Julián Alvarez para fundar el establecimiento y marca de tabacos "Henry Clay», empresa en la que acumuló suficiente capital como para dejarla en cuatro años y dedicarse exclusivamente a la fundación de una casa de banca que «al rendirle respetables ganancias, coloca al Sr. Bances entre los principales hombres de negocios de La Habana» (39).

En 1880 su casa de banca giraba letras en todas cantidades a corta y larga vista sobre las plazas españolas, Londres, París y Nueva York. Desde 1876 había obtenido de José Partagás, hijo del difunto Jaime Partagás que había sido el fundador de la famosa marca que llevaba su nombre, por pacto de retro la marca de tabacos «Flor de Tabacos Partagás» formando una sociedad con él. José Partagás fue socio comanditario hasta 1879 en que quedó disuelta la sociedad y Bances permaneció como dueño absoluto de la marca y el establecimiento, fundando entonces una empresa de mayores proporciones, al invertir 1.200.000 pesos, ampliando la producción a gran escala de tabacos, cigarrillos y picadura. En estas ocupaciones empleaba un total de 1.200 operarios que procesaban unos $408.000 \mathrm{~kg}$. de rama de Vuelta Abajo. Sus negocios no se limitaron a la manufactura y a la

(36) ANC. Fondo Registro Mercantil de la Habana, tomo II, folio 87, hoja 58.

(37) El Tabaco. 13 de febrero de 1881. Año II, $\mathrm{n}^{2} 21$, pág. 5

(38) Ibidem.

(39) Ibidem. 
banca, sino que figuró entre los pocos empresarios que detentaron las contratas para exportar tabaco en rama y torcido a España. De la preminencia social que llegó a tener Bances en el período basta señalar que fue distinguido por el gobierno español con importantes cargos en los cuerpos consultivos de la administración colonial. Figuró también activamente al frente de un Batallón de Voluntarios y fue uno de los empresarios que más luchó para crear un organismo del sector, lo que logró exitosamente en 1880 con la fundación del Gremio de Fabricantes de Tabacos, del que fue su primer presidente (40).

Otro exponente importante de este proceso fue Henrique Upmann, alemán que en 1844 había fundado una discreta fábrica y expendeduría de tabacos conocida como $\mathrm{H}$. Upmann, y que fue progresando paulatinamente lo que le permitió en la década del sesenta adquirir importantes propiedades agrícolas tabacaleras. Este hecho lo ubicaba ya entre los grandes empresarios de la época, con grandes almacenes en la calle Cuba, intramuros de la ciudad. Sus productos eran cotizados en las más importantes plazas de Europa y de Estados Unidos, en los años ochenta muda su manufactura a locales más amplios en la céntrica calle San Miguel, aunque mantuvo los almacenes en la misma dirección, cerca del puerto. Ya a mediados de la década del noventa construyó una enorme edificación en la esquina de Carlos III y Belascoaín, con grandes depósitos de materia prima. Upmann tenía importantes nexos comerciales con la firma neoyorquina de tabacos Seidenberg y Cía. (41) y llegó a ser uno de los más grandes contratistas del comercio tabacalero con España, resultando acusado varias veces de "monopolizar» ese mercado, pues él concentraba las ventas de tabaco en rama y elaborado con ese destino. Durante los años ochenta celebró también importantes contratas comerciales de tabaco con el gobierno francés.

Abarcó todas las fases productivas del renglón, agrícola, manufacturera, comercial, y se dedicó a la venta al por mayor de tabaco en rama. Hay noticias de que desde 1871 existía una sociedad que giraba en la plaza de La Habana bajo la razón de H. Upmann y Cía. En 1897 se disolvió y al parecer estaba integrada por Henrique Upmann, Juan Runken, Guillermo Rochele y Herman Upmann; separado Rochele, los Upmann se hicieron cargo de todas las existencias y valores, formando una nueva sociedad con Runken para la elaboración y venta de tabacos,

(40) Ibidem.

(41) El Tabaco. 13 de febrero de 1881. Año Il, n² 21 pág. 6. 
con la firma $\mathbf{H}$. Upmann y Cía. Los gerentes eran Henrique Upmann, Juan Runken, mientras que Herman Upmann era comanditario. El capital ascendía a 350.000 pesos, aportados 200.000 o por Henrique y 150.000 por Herman. Todas las marcas eran propiedad de Henrique Upmann que en esa fecha totalizaban 56. Esa sociedad fue prorrogada en 1889 y ya aquí se registraba que se dedicaría a utoda clase de negocio de lícito comercio» (42). En 1893 una nueva prórroga con 370.000 pesos de capital social y 27 marcas más, denotan su extraordinaria sólidez, que a la vuelta del siglo le permitió resistir las propuestas del trust norteamericano. Según González del Valle. H. Upmann rechazó la oferta de 1.000 .000 pesos por el hierro de su marca «acompañada del compromiso de adquirir edificio y existencias al precio que se pactase» (43).

\section{PENETRACión DE CAPITALES FORÁNEOS}

Todo ese proceso de concentración, expresado básicamente a través de la centralización de capitales, se había venido produciendo en los marcos financieros cubanos, con cierta celeridad desde los años sesenta y fue la nota predominante de la evolución de la industria tabacalera en ese período hasta que se produjo la penetración de capitales extranjeros. El primer signo de este fenómeno se produjo en noviembre de 1888 con la constitución de la primera sociedad anónima del sector, la "Henry Clay and Bock Co. Limited», radicada en Londres y con sucursal en La Habana; con el objetivo de fabricar y vender tabacos, cigarros y paquetes de picadura. El capital constitutivo era de procedencia inglesa y ascendía a 330.000 libras esterlinas divididas en 33.000 acciones de 10 libras cada una. Entre los siete gerentes figuraban el alemán Gustavo Bock y el cubano Francisco de Paula Alvarez Muro, que residían en La Habana (44). Ambos por separado habían logrado durante la segunda mitad del siglo consolidar distintas empresas tabacaleras, a través de la centralización del capital, por lo que este hecho facilitó la absorción de que fueron

(42) ANC. Fondo Gobierno General. Leg. 88, no 3574, Fondo Registro Mercantil de La Habana, tomo I, folio 58 v, hoja 19; idem, y tomo LXXVIII, folio 1566, hoja 171.

(43) González [12], págs. 6-7.

(44) La gerencia de la sociedad fue integrada por siete miembros, R. W. Grosvenor, Arthur Campbell, Robert Monckton, Robert W. Willis, Edwin F. Botouright, todos ingleses residentes en Londres, además de Alvarez y Bock. 
objeto sus negocios. Francisco Alvarez había logrado un sólido crédito en la producción y venta de tabacos y cigarros, a través de la sociedad mercantil "Alvarez y González" (45), que llegó a concentrar más de treinta marcas importantes, entre las que se destacaba la famosa "Flor de Henry Clay» fundada por Julián Alvarez a mediados de siglo. Además había adquirido marcas de Alfredo Nogueras, George G. Nichole, residente en Nueva York, y de las compañías Best Russell y Reid Mundock, ambas de Chicago. Sus marcas y fábrica con todas las pertenencias las vendió a la mencionada sociedad anónima en 750.000 pesos.

El alemán Gustavo Bock era otro importante empresario tabacalero que tenía propiedades agrícolas y desde los años setenta había participado en diferentes sociedades mercantiles con Benito Celorio y Pedro A. Estanillo respectivamente, para la producción y venta de puros. También se destacaba entre los grandes exportadores de hoja, con un espacioso almacén que explotaba a través de la sociedad Bock, Pacheco y Cía. (46). La marca principal que explotaba era "El Aguila de Oro» y las anexas «Fausto» y "La Moscovita», todas arrendadas por él a su propietaria Ana E. Keene, que residía en Chicago. En 1888 Bock le compró a esta las marcas por 18.800 pesos y ese mismo año adquirió por título de compraventa de Pedro A. Estanillo cinco de sus mejores marcas, de forma tal que cuando integró la sociedad anónima recibió por todas ellas y por su fábrica 300.000 pesos (47). Desde 1889 Bock tuvo a su cargo la firma de la sociedad. Esta en pocos años adquirió las marcas de la extinta sociedad de Fueyo y Cía., las de Ignacio Prado y Sánchez, las de Ignacio Olmo y Piedras y las de M. S. Cussi y sobrinos. También explotaba la fábrica y marcas "La Intimidad» de las hermanas Emilia y Antonia Caruncho y Becerra, que las arrendaron por 700 pesos (48).

En 1898 la Habana Cigar and Tobacco Factories Ltd. de Londres subsumió esta sociedad con un capital de 520.000 libras esterlinas, ampliando los negocios y adquiriendo nuevas fábricas

(45) La marca "Flor de Henry Clay» aparece registrada a nombre de Julián Alvarez desde 1874 hasta 1883. Es probable que la sociedad de Alvarez González surgiera por esos años, esta la integraban como únicos socios Francisco Alvarez y Francisco González Alvarez.

(46) Directorio general y comercial de La Habana e isla de Cuba. La Habana, Imprenta Militar, Depósito General, 1874; Anuario del Comercio de la industria de la magistratura y de la administración, o directorio de la isla de Cuba, e indicador de las de Madrid, 1883; El Tabaco. $1^{\circ}$ de agosto de 1880. Año I, n² 3, pág. 8.

(47) ANC. Fondo Registro Mercantil de La Habana, tomo II, folio 87, hoja 58 y tomo XV, folio 73 , hoja 722 .

(48) Ibidem, 2." sección, tomo XIX, folio 79. 
y propiedades, como la fábrica y marcas de la sociedad de Segundo Alvarez y Perfecto López, mencionada con anterioridad, las fábricas de Prudencio Rabell nombradas "La Intimidad» y «La Legitimidad», y marcas importantes del empresario Cueto y Hno., entre otros. El director y representante en La Habana siguió siendo Gustavo Bock. En 1899 se estimaba que a esta sociedad pertenecían cerca de las $3 / 4$ partes de las mejores tierras tabacaleras de San Luis y las 2/3 partes de las de la localidad de Remates, todas ubicadas en la cotizada región de Vuelta Abajo. Concentraba la producción de ocho grandes manufacturas y según González del Valle aglutinaba nueve marcas principales de tabacos, 102 marcas anexas y 41 de cigarrillos y picaduras (49).

Fue precisamente en 1899 cuando se produjo la irrupción en Cuba de los monopolios tabacaleros norteamericanos, que en breve plazo aceleraron el proceso. El estudio del fenómeno de penetración rebasa los marcos cronológicos de este trabajo, en tanto su evolución abarcó las primeras décadas del siglo XX, sin embargo resulta de interés apuntar algunas cuestiones que en buena medida culminaron el período tratado. Hasta entonces los intereses de Estados Unidos en cuanto al tabaco cubano se habían circunscrito a la esfera comercial, resultando durante años el principal receptor del producto insular, tanto en cuanto al torcido como a la rama. Pero el crecimiento acelerado de la industria tabacalera norteamericana fue incidiendo desfavorablemente en las posibilidades comerciales del habano en ese mercado, afectado por diferentes aranceles proteccionistas, como los de 1857 y 1883, que se inclinaban a limitar la entrada de puros y favorecían en general la de materia prima, en función de estimular el desarrollo de sus propias manufacturas, protegiéndolas de la competencia. Ya en la década del noventa, con el desarrollo de las primeras corporaciones monopólicas, esta tendencia se recrudece y se va modificando sensiblemente el carácter de la línea proteccionista: es más agresiva y a diferencia del período anterior en que se trataba de contribuir al desarrollo de

(49) El Tabaco. noviembre-diciembre de 1899. Año I, $\mathrm{n}^{0} 4$ y $\mathrm{n}^{2}$ 5; ANC. Fondo Registro Mercantil de La Habana, tomo XXXVII, folio 26, hoja 2239. Las fábricas de la compañía Henry Clay and Bock Co. Limited fueron: Henry Clay, sita en Luyanó $n^{0}$ 100; La Corona sita en Reina $n^{Q} 1$; La Intimidad Sita en Belascoaín $n^{9}$ 38; El Aguila de Oro sita en Concepción nos. 3 y 5; La Española sita en Consulado nos. 91 y 93; D. Quijote de la Mancha y Flor de Navas sitas en Estrella $n^{9}$ 19; La Estrella sita en Marques González esq. Zanja, 41; La Rosa de Santiago sita en Belascoaín $\mathrm{n}^{0}$ 2c. De acuerdo con los datos publicados por GONZÁlez, [12], pág. 64. y 65. 
la industria nacional, de lo que se trata ahora es de monopolizar el mercado interno. De hecho los empresarios cubanos comenzaron a ver cada vez más distante el mercado tradicional del habano, lo que se hizo ostensible cuando se puso en efecto el Bill Mc Kinley en 1890, a través del cual se elevaron los aranceles de 2,50 a 4,50 por libra de puros, manteniendo el $25 \%$ ad valorem y en cambio la entrada de materia prima resultaba favorecida por 0,35 la tripa, 0,15 la rama despalillada y 2,00 la capa, esta última después se rebajó (50). Los marquistas al analizar las bases del arancel, resumieron de esta forma sus apreciaciones sobre las consecuencias del mismo para el negocio insular:

con los gastos de fletes, comisión etc., no podrá venderse el millar de tabaco habano en los Estados Unidos a menos de 134 a 138 y a 0.15 cada tabaco al detalle, y aunque se trata de un país rico es imposible seguir fumando nuestro tabaco. Perderemos un mercado que consume de 100 a 110 millones de tabacos anuales, por valor de 5 millones a 5.500 .000 y sobre cien mil tercios por valor de otros 500.000 exactamente la mitad de nuestro comercio en este ramo (51).

Por otra parte se venía acumulando también toda una carga de contribuciones, impuestos, etc., restricciones comerciales con otros mercados, como consecuencia de la política de España en cuanto al tabaco, que era considerado por la Corona como un artículo especialísimo de «renta». En la propia década del noventa virtualmente se perdieron el mercado alemán de habanos y el suramericano. La combinación de ambos factores, o sea, de la política fiscal y comercial de España en cuanto al tabaco insular y el desarrollo en Estados Unidos de la producción tabacalera sobre bases monopólicas hacia 1890, fue entorpeciendo progresivamente el universo económico del marquista insular y ya por esta fecha resultaba más económico en sentido general, elaborar el puro fuera de Cuba, con la rama cubana, que en las propias manufacturas insulares.

A mediados de los noventa y sin contar los gastos de fletes, comisión y otros, un millar de tabacos torcidos con precio corriente en plaza de 50, tenía que satisfacer por derechos al ser

(50) Unión de Fabricantes de Tabacos de La Habana. Memoria de los trabajos más importantes realizados desde el 18 de septiembre de 1890 hasta el 5 de lebrero de 1894, en délensa de los intereses generales de la industria que representa. Imprenta La Razón, La Habana, 1894. págs. 13-16.

(51) Ibidem. 
exportados a Estados Unidos 67,85, mientras que cualquier fabricante radicado allí, al transportar la rama de Cuba para elaborar la misma cantidad de tabacos, sólo tenía que pagar por derechos 12,27; resultando de ello una sensible diferencia de 55,58 en favor del productor foráneo y en detrimento del insular (52).

La intervención y ocupación de la isla en enero de 1899 por los Estados Unidos creó lógicamente una situación mucho más difícil para los empresarios que se habían venido debatiendo en medio de estas dificultades para sostener el nivel de las exportaciones, y estaban conscientes del riesgo que para sus negocios tenía el predominio político de Estados Unidos en Cuba. Por otra parte eran ellos en su inmensa mayoría españoles y muchos como se ha visto estaban seriamente comprometidos con el depuesto régimen colonial. Pero lo más importante es que después de la guerra los intereses monopolistas pudieron consolidar aún más los controles proteccionistas y de hecho siguó siendo más barato producir el tabaco en Norteamérica con la misma hoja cubana.

El desenlace no se hizo esperar. En el mes de marzo de 1899 la recién creada sociedad anónima Havana Commercial Co. de New Jersey, otorgó amplios poderes al conocido comerciante Francisco García López, que tenía importantes almacenes de exportación de tabaco en rama, con casas comerciales en La Habana y Nueva York, para que "compre todas las propiedades raíces, muebles y semovientes o de cualquier otra clase, derechos y acciones que crea necesarios para la compañía otorgante en la Isla de Cuba, por los precios, y bajo los términos que juzgue más conveniente» (53). Francisco García había vendido a esta Corporación sus empresas comerciales por medio millón de dólares y habiendo sido nombrado director en La Habana de esa sociedad, se dio a la tarea de adquirir a crecidos precios los hierros y demás propiedades de una parte importante de las manufacturas habaneras. Esta sociedad había sido fundada para adquirir expresamente entidades del tabaco cubano y al parecer era una sucursal de la American Tobacco Co. Prácticamente en meses, la compañía norteamericana adquirió los negocios de la viuda de Juan Valle Fernández con su famosa fábrica "La Flor de Cuba" y

(52) Unión de Fabricantes de Tabacos y Cigarros de La Habana. Informe acerca de la grave situación en que se encuentran las industrias tabacaleras, causas de su descendencia y medidas que se consideran necesarias para salvarlas de la ruina que las amenaza. Habana, 1900. pág. 37. 2.359 .

(53) ANC. Fondo Registro Mercantil de La Habana, tomo 40, folio 101, hoja 
todas sus propiedades; otro tanto sucedió con la sociedad de Pino y Villamil, que habían explotado "La Africana»; también compraron "La Carolina» a la sociedad Bances y Suárez y nueve empresas más con las mismas características, hasta un total de doce fábricas y marcas principales, con 149 anexas de tabacos y 36 de cigarrillos y picadura (54).

En la prensa se publicó entonces que Francisco García había vendido a la sociedad terrenos de Remedios que él había adquirido en 1897. Además había arrendado terrenos en importantes zonas de Vuelta Abajo como San Luis, San Juan y Martínez y en los Remates de Guane (55). Al final de los primeros seis meses de establecida la sociedad en Cuba, su presidente declaraba a una revista londinense que las ganancias de la compañía equivalían a un dividendo del $7 \%$ (56).

A través de esta corporación y de otras que se fueron creando sucesivamente, se produjo con mayor agudeza la concentración de la producción, pero ahora muchas de las empresas mencionadas que habían venido evolucionando en los marcos insulares, comenzaban a formar parte de un engranaje imperialista, que trajo aparejado un proceso de desindustrialización y descapitalización en el renglón tabacalero en su conjunto.

A diferencia de lo que ocurría en las empresas de mediados de siglo y aún en la década del ochenta, en los negocios del Trust, la razón empresarial última no era diseñada por intereses cubanos, sino que en la misma medida que las industrias vitales y las mejores tierras tabacaleras comenzaron a formar parte de una estructura definida de carácter mundial, en la cual el cultivo, la producción y la distribución estaban en función ganancial de los monopolios tabacaleros, se fue desarticulando una estructura que antes se encontraba circunscrita a los marcos nacionales y generaba cuotas de ganancias de importancia insular.

Las aspiraciones de los marquistas de antaño - que con tanto empeño habían denunciado en todas las tribunas la creciente exportación de la rama y la necesidad de allegar fórmulas viables que propiciaran la rápida colocación del producto en la mayor cantidad de mercados consumidores posibles- quedaban como

(54) González del Valle registra las siguientes fábricas, algunas de las cuales se pudieron constatar a través del Registro Mercantil: La Africana, La Antiguedad, La Comercial, La Carolina, La Flor de Cuba, La Rosa Aromática, La Meridiana, La Flor de Inclán, La Vencedora, Manuel Garcia Alonso, El Siboney, A. de Villar y Villar.

(55) El Tabaco. noviembre de 1899. Año I, no 4, pág. 2.

(56) Ibidem, diciembre de 1899. Año I, n 5, pág. 15. 
alegatos anacrónicos en esta nueva estructura que justamente se interesaba más en contar con un proveedor eficaz de materia prima para sus grandes centros procesadores, que en propiciar la consolidación de una industria para ellos periférica. 